\title{
TRANSTORNOS MENTAIS: NEUROPSICOLOGIA E APRENDIZAGEM
}

\author{
Clinaura Maria de Lima ${ }^{1}$
}

RESUMO: O presente artigo versa sobre transtornos mentais e os aspectos de aprendizagem em contexto de neuropsicologia. A partir desta ótica, uma indagação importante surgiu: quais seriam os aspectos interdisciplinares que sustentam as abordagens da neurociência, educacionais e neuropsicológicas, a respeito da clínica voltada para os graves prejuizos escolares, como as dificuldades de aprendizagem? Para o estudo, utilizou-se revisão bibliográfica em que se procurou esclarecer as hipóteses: a) Se transtornos mentais e as concepções do cérebro, provocam dificuldades de aprendizagem; b) E de que forma a escolarização e seu processo interdisciplinar, permitem maior benefício ao educando; c) A

\footnotetext{
Mestre em Psicologia Clínica pela Universidade de Brasília - UNB-2007. Dissertação sobre abuso sexual infantil. Possui graduação em PEDAGOGIA pela Universidade Católica de Brasília (198I) e graduação em PSICOLOGIA pela Universidade Católica de Brasília (2004). Pós-graduação em Psicopedagogia pela Universidade Federal do Rio de Janeiro - UFRJ, Didática do Ensino Superior pela Universidade Católica de Brasília - Pós graduação em Neuropsicologia- IPOG-DF. Especialista-202I. Formação em EMDRDessensibilização e Reprocessamento do trauma através de movimentos oculares-2018. Trabalhou na Pós graduação em Psicopedagogia, faculdades ICESP, no período de 2008 a 2016, coordenando os laboratórios de psicopedagogia Preventiva e Interventiva, em estágios supervisionados nas escolas públicas e ministrando aulas neste laboratório, além da docência nas seguintes disciplinas: Psicolinguística e o Processo da Linguagem, Epistemologia Genética, Diagnóstico e Intervenção Psicopedagógica, Psicanálise Aplicada à Educação.. Ministrou aulas na Pós graduação em Psicologia Organizacional, nas seguintes disciplinas: Medicina Qualidade de Vida e Segurança no Trabalho, Iniciação cientifica e TCC- Trabalho de Conclusão de Curso. Exerceu Docência no curso de graduação em Recursos Humanos, com as disciplinas: Politicas de Recursos Humanos, Avaliação de Desempenho. Docente do curso de Pedagogia-ICESP no período de 2003 a 2017, com diversas disciplinas: Pedagogia Terapêutica, Psicopatologia Aplicada à Educação, Fundamentos da Educação Infantil, Psicomotricidade Aplicada à educação, Teorias da Aprendizagem, Psicologia Aplicada à educação, Educação Infantil e desenvolvimento da Linguagem, Fundamentos da Psicopedagogia, Educação Infantil Desenvolvimento e Linguagem. Docente do curso de Psicologia no período de 2018 a 2021 com diversas disciplinas, entre elas Psicologia Ciência e Profissão, Psicologia da aprendizagem, terapia de grupo, psicologia jurídica, Estagio III e IV, Psicomotricidade, também na unidade de Luziânia-GO UNIDESC. Atuou no curso de graduação em Direito, com a disciplina Psicologia Aplicada ao Direito, de 20213 a 2021. Desenvolve pesquisa cientifica na área de Violência contra as mulheres e as questões de gênero, Feminicidio e a Lei Maria da Penha, projeto A Força Feminina, ainda não publicado. Desenvolve projetos nas áreas de Intervenção, nos aspectos dos transtornos escolares com crianças e adolescentes. Ministra diversos curso pela plataforma VIVEREAD.COM.BR nas áreas do Direito, Psicologia e Educação Atende em consultório na área de Psicologia Clínica infanto-juvenil e adulto, abordagem Psicodinâmica Breve. Participou do Núcleo de Orientação Psicopedagógica NOP- atendimento psicopedagógico(crianças, adolescentes e adultos) em Faculdades Promove de Brasília, por io anos. Escritora com três livros lançados, sendo dois pela editora Juruá. Infância ferida: Os Vínculos da criança abusada sexualmente em seus diferentes espaços sociais. Psicopedagogia: Prática, Vivencias e Experiências no espaço Escola e Clinica. Lançamento autoral. Brisa: A Borboleta de Asas Partidas. Projeto Cristal. Atendimento com crianças de 06 a 12 anos que vivenciaram maus tratos e abuso sexual. Projeto Cultural Saia Literária. E-mail: clinaura.lima@gmail.com.
} 
ausência de Avaliação psicológica interfere no processo ensino aprendizagem. Definiu-se como objeto de estudo investigar os transtornos mentais e sua correlação com a escolarização $e$ as dificuldades de aprendizagem em jovens adolescentes. Buscou-se aqui refletir, juntamente com diversos autores, o quanto as manifestações dos comportamentos e sintomas de ansiedade, medo e pânico provocam prejuizos funcionais na aprendizagem dos jovens adolescentes. Conclui-se que a existencia de transtorno mental pode exercer forte interferencia no processo de escolarização, afetando a aprendizagem, provocando sofrimento na estrutura emocional e social dos jovens,

Palavras-chave: Transtornos. Aprendizagem. Avaliação neuropsicológica.

\section{INTRODUÇÃO}

A proposta de pesquisa ora desenvolvida, sob a temática transtornos mentais: neuropsicologia e aprendizagem, compõe itens de extrema complexidade, notadamente marcado por diversas nuanças e formas, representados por um contexto social, histórico, político e cultural que perpassa o cotidiano familiar, as fases do desenvolvimento e o processo ensino aprendizagem, envolvido pelo insucesso nas aprendizagens, baixo nível de produção e escolarização.

Como psicóloga, pedagoga, psicopedagoga e, recentemente, especializada em neuropsicologia me deparei com a seguinte indagação: constatam-se incriveis avanços da Neurociência que, juntamente com a Neurobiologia das emoções, muito contribui para o enriquecimento do processo ensino-aprendizagem. Por que, então, não utilizar-se de tais estudos para aprimorar e avaliar os problemas de aprendizagem no âmbito escolar e clínico, proporcionando um melhor acesso à educação? De acordo com Cosenza e Guerra (201I), a relevância atribuída à neurociência, diz respeito à mobilização de recursos cognitivos, entre eles a raiva, o medo e a ansiedade, pois podem atrapalhar o processo de ensino aprendizagem. Logo, imagina-se a importância de educadores, psicólogos e demais profissionais, que formam equipes multidisciplinares, compreenderem, que seja fundamental, o conhecimento cientifico, a respeito das funções e estruturas cerebrais, assim como o trabalho interdisciplinar para a superação das dificuldades de aprendizagem nos mais diversos contextos de inserção de jovens adolescentes, criando também metodologias de ensino mais eficazes. 
Depreende-se, então, que do ponto de vista neurobiológico, os principais circuitos e sistemas cerebrais envolvidos no processamento das emoções são: corpo amigdaloide, sistema límbico, área orbitofrontal, hipotálamo, circuito dopaminérgico (especialmente o núcleo acumbente), sistema nervoso autônomo, os sistemas endócrino e musculoesquelético, córtex cerebral, hipocampo e o sistema ativador reticular ascendente. No que se refere ao sistema límbico, vários neurocientistas consideram que ele é o grande centro modulador das emoções (LENT, 2010; VIVAN, 2012; TERUEL; 2013; GIL, 2014; KANDEL et al., 20I4; OLIVEIRA; PEREIRA; VOLCHAN, 20I6), sendo conceituadado como o "[...] conjunto de estruturas corticais e subcorticais interligadas morfologicamente e funcionalmente, relacionadas com as emoções e a memória" (MACHADO; HAERTEL, 2014, p. 263).

Sabe-se que excelentes instrumentos neuropsicológicos, além de várias estratégias metodológicas, vêm sendo aplicados às solicitações de insucesso escolar, imbricadas ao processo de aprendizagem e aos graves prejuizos escolares, em especial, em jovens adolescentes portadores de transtornos mentais. É nesse contexto que surgiu a questão do estudo: quais seriam os aspectos interdisciplinares que sustentam as abordagens da neurociência, educacionais e neuropsicológicas, a respeito da clinica voltada para os graves prejuizos escolares, como as dificuldades de aprendizagem? E as hipóteses: a) Se transtornos mentais e as concepções do cérebro, provocam dificuldades de aprendizagem? b) E de que forma o processo de escolarização e a interdisciplinaridade, permitem maior beneficio ao educando; c) A ausência de Avaliação psicológica interfere no processo ensino aprendizagem?

Em resposta à questão e em busca de esclarecimento das hipóteses, o estudo é teóricobibliográfico, marcado pelo olhar epistemológico interdisciplinar da neurociência e da neuropsicologia. Nessa perspectiva, o escopo da pesquisa é de contribuir com novos estudos e possibilidades de uma plausível clínica neuropsicológica para a superação de problemática psíquica da contemporaneidade. Percebe-se o psiquismo como uma emergência do corpo e com ele a cognição, Rouco (2020) e Soussumi (2015;2020) observam que não se pode falar em domínio psíquico sobre o corpo sem um trabalho integrado corpo/psíquico com vistas à sobrevivência do sujeito. Tal perspectiva, segundo Guerra: Leonor (20II) propõe a integração 
de saberes e corrobora a melhor compreensão dos mecanismos afetivos, vinculares, envolvidos na vida cotidiana e na prática clínica, ações de acolhimento ao sofrimento psíquico humano.

Por outro lado, ainda na linha de pensamento de Guerra: Leonor (20II)

Educar é proporcionar oportunidades e orientação para aprendizagem, para aquisição de novos comportamentos. Comportamentos resultam da atividade cerebral. O cérebro, portanto, é o órgão da aprendizagem. As descobertas das neurociências estão esclarecendo alguns dos mecanismos cerebrais responsáveis por funções mentais importantes na aprendizagem. No entanto, a aplicação desse conhecimento no contexto educacional tem limitações. As neurociências não propõem uma nova pedagogia, mas fundamentam a prática pedagógica que já se realiza, demonstrando que estratégias pedagógicas, que respeitam a forma como o cérebro funciona, tendem a ser mais eficientes. Conhecer a aprendizagem numa perspectiva neurobiológica pode auxiliar educadores, professores e pais, a compreender alguns aspectos das dificuldades para aprendizagem e inspirar práticas educacionais, mas não possibilita a prescrição de receitas para a solução dos problemas da educação. Aprendizagem não depende apenas do funcionamento cerebral (GUERRA,20II)

Contudo, ainda nesta linha da aprendizagem e do contexto escolar, Muniz (2012) ressalta que gestos de confiança, apoio e carinho também são elementos essenciais na relação entre o professor e o aluno (ex: um sorriso, um reconhecimento acompanhado de um toque afetuoso ou um abraço), o contato pele com pele possibilita a transmissão de mensagens positivas em um feedback, considerado o maior transmissor do estado emocional.

Portanto, na produção desse artigo, o entendimento é de considerar nessa visão de abordagem interdisciplinar, que se justifica pela discussão e recorte com o contexto educacional, delimitando as ações e imbricações dos transtornos mentais e suas implicações para o processo de aprendizagem, ao invés de lidar com a transdisciplinaridade, que permite um contexto mais amplo, que neste presente estudo não contempla o objeto em foco. Por outro lado, se as neurociências explicam a materialidade neural do pensamento, a neuropsicologia, por sua vez, propõe o estudo da cognição, que permite uma aferição pontual das habilidades e dificuldades de um individuo, além de possibilitar a interface entre a pscologia e neuropsicologia, com vistas a um processo de intervenção (SEABRA, 20II).

Embora seja fato, à luz dos esclarecimentos de COSENZA, R. M.; GUERRA, L. B. (20II) que apontam importantes contribuições das neurociências que fundamentam a prática 
educacional (Kolb; Whishaw, 2002; Koizumi, 2004; Blakemore; Frith, 2005; HerculanoHouzel, 2005; Rotta; Ohlweiler; Riesgo, 2006; Blake; Gardner, 2007; Conselho Nacional de Pesquisa dos Estados Unidos, 2007), o presente artigo não esgota em sua discussão, contornos frágeis ou confusos, a respeito de temas emblemáticos como transtornos mentais, ansiedade e depressão em contexto de aprendizagem. Assim, trabalha-se com autores como (CAPOVILLA,F.C, 2016, SEABRA, 20II,GUERRA, 20II, BRANDÃO, 2014) entre outros que, em suas pesquisas, discutem interlocuções que acercam as emoções, cognição, afetos e plasticidade cerebral.

O contato com este estudo, portanto, possibilitou enxergar o emaranhado de dificuldades pedagógicas, emocionais e sociais a que os indivíduos estão expostos, ao mesmo tempo em que requerem um esclarecimento, atitudes e inovações sob um novo olhar das ciências psicológicas e educacionais, além de contar com as importantes contribuições da neurociência e da neuropsicologia, no que diz respeito ao processo de escolarização e aprendizagem. Isso provocou um desejo irresistível em trabalhar essas questões neurobiológicas e, ao mesmo tempo, estudar, pesquisar e aprofundar a respeito dos transtornos mentais e os graves prejuízos escolares.

Procurou-se organizar o texto da seguinte forma: no primeiro eixo, discute-se transtornos mentais e adolescência, correlações de sintomas e comportamentos a respeito do funcionamento da cognição e do desempenho escolar. No segundo eixo,

discute-se o processo de aprendizagem humana e as dificuldades de aprendizagem.

Também busca-se esclarecer o contexto familiar e o adoecimento mental, a extensão do adoecimento e a sobrecarga sobre o sujeito em terapia, que vivencia o insucesso escolar e o sofrimento psiquico.

\section{DESENVOLVIMENTO}

\section{I Transtornos mentais e adolescência}

\subsection{O processo de aprendizagem humana}

Pouco tem se discutido, a respeito dos transtornos mentais, em especial na adolescência. $O$ assunto torna-se mais confuso, quando estão envolvidos aspectos da aprendizagem e escolarização, isso porque o significado da palavra transtorno mental esta 
"envolto" em um estigma de loucura e insanidade, ao mesmo tempo, em que, o próprio contexto escolar, mostra-se impotente, "apavorado" frente aos desafios para trabalhar a interdisciplinaridade dos saberes, diante de uma avaliação neuropsicológica, ou mesmo de um diagnóstico psicológico, que aponta transtorno mental, em pessoas tão jovens.

Discorrer a respeito de transtorno mental não é uma tarefa fácil; permeada de rótulos e complexidades, a literatura sempre lidou com dificuldades em esclarecer, com objetividade, sobre o conceito de transtorno mental. Sabe-se que a história da loucura, assim como os pressupostos teóricos, metodológicos, além da trajetoria da psiquiatria com a saúde mental, deixou marcas profundas, tanto nas instituições, quanto na sociedade, assim também na identidade humana, daquelas pessoas que desenvolveram estes transtornos e que conviveram de perto com o isolamento e a hospitalização, internação em manicômios, de forma interminável. Todos esses percalços contribuíram para a formação de uma cultura bastante torturante, ameaçadora e discriminatória, que se arrasta ao longo do tempo. Quebrar todos esses paradigmas e ranços dos tratamentos e percepções, a respeito dos transtorno mentais, tem sido um desafio da neurociência e principalmente das ciências psicológicas. Percebe-se uma esforço muito grande da psiquiatria em modernizar seus métodos e técnicas, inovando, com um outro olhar, o tratamento dos transtornos mentais.

No Brasil, a Câmara Federal aprovou em 17.03.09, em caráter conclusivo, o Projeto de Lei 6or3/or, do deputado Jutahy Junior (PSDB-BA), que conceitua transtorno mental, padroniza a denominação de enfermidade psíquica em geral e assegura aos portadores desta patologia o direito a um diagnóstico conclusivo, conforme classificação internacional. $O$ projeto determina que "transtorno mental" é o termo adequado para designar o gênero enfermidade mental, e substitui termos como "alienação mental" e outros equivalentes retirados.

É de suma importância o conhecimento sobre o Manual de Diagnóstico e Estatístico de Transtornos Mentais em sua 5. a edição ou DSM-V feito pela Associação Americana de psiquiatria para definir como é realizado o diagnóstico de transtornos mentais. Esta escala é utilizada pelos profissionais da saúde, entre eles: médicos, psicólogos, fonoaudiólogos e terapeutas ocupacionais. Essa versão DSM-V é a mais recente. O conhecimento desse 
manual é imprescindivel para lidar com as ações de avaliação e diagnóstico. Dessa forma, compreende-se a necessidade de informações, a respeito deste manual.

$\mathrm{O}$ advento do DSM-V, lançado em 2013, após exaustivas pesquisas, em seus 12 anos de estudo, conseguiu garantir uma nova classificação mais estrutural sob os novos olhares da psiquiatria, que embasada para a aplicação da pesquisa, procura apontar uma reflexão mais estrutural sobre a classificação dos transtorno rompendo com o modelo multiaxial, introduzido na terceira edição do manual.

O que significa transtorno mental? A literatura destaca diversos conceitos e definições, com finalidade de simplificar, o significado conceitual a respeito dos transtornos e apresenta a seguinte definição: De acordo com o Dr. Osvaldo Lopes do Amaral Diretor Clínico do INEF - Instituto de Estudos e Orientação da Família:

\footnotetext{
Transtornos mentais são alterações do funcionamento da mente que prejudicam o desempenho da pessoa na vida familiar, na vida social, na vida pessoal, no trabalho, nos estudos, na compreensão de si e dos outros, na possibilidade de autocrítica, na tolerância aos problemas e na possibilidade de ter prazer na vida em geral”. (2003:01).
}

Ainda segundo este mesmo autor, os transtornos provocam sintomas, tais como desconforto emocional, distúrbio de conduta e enfraquecimento da memória. Algumas vezes, doenças em outras partes do corpo afetam a mente; outras vezes, desconfortos, escondidos no fundo da mente, podem desencadear outras doenças do corpo ou produzir sintomas somáticos.

De acordo com REY (1999: 23-24) : “doença mental é um termo geral para os distúrbios da mente, afetividade, percepção e comportamento, com manifesta incapacidade resultante dessas perturbações percebidas tanto pelo paciente como pelos seus próximos”. Alguns exemplos de doenças, ou transtornos mentais podem ser destacados, conforme DALGALARRONDO (2008) em: Neurose - termo geral para transtornos psíquicos, sem grave ruptura com a realidade, em que não se evidenciam lesões orgânicas. A neurose é caracterizada por um comportamento anormal, podendo revestir formas múltiplas. A neurose perturba a afetividade, mas não a atividade intelectual.

Psicose - Termo geral para transtornos mentais graves, marcados por flagrante ruptura com a realidade, alterando a percepção e a compreensão da realidade, 
desorganizando o comportamento afetivo e social, sem que os pacientes tenham, em geral, consciência do caráter patológico de tais fatos.

Esquizofrenia - Grupo de afecções mentais crônicas, de causa desconhecida, que constituem o tipo mais frequente de psicose e cujo quadro clínico é marcado por distorções características do pensamento (delírios) e da percepção (alucinações), assim como por afetos inapropriados ou embotados.

Os transtornos mentais, em geral, resultam da soma de muitos fatores, tais como: Alterações no funcionamento do cérebro; - Fatores genéticos; - Fatores da própria personalidade do indivíduo; - Condições de educação; - Ação de um grande número de estresses; - Agressões de ordem física e psicológica; - Perdas, decepções, frustrações e sofrimentos físicos e psíquicos que perturbam o equilíbrio emocional. Qualquer ser humano, ao longo de sua vida, poderá ser acometido de desequilíbrio mais ou menos profundos e, dependendo da intensidade do seu sofrimento e de suas condições mentais básicas, poderá ser um transtorno mental mais grave ou menos grave, mais recuperável ou menos recuperável, mais passageiro ou mais permanente (AMARAL, 2011: 02)

A literatura salienta que o custo social dos transtornos mentais é bastante elevado em diversos setores da vida; além do sofrimento humano, afeta de forma profunda, aspectos profissionais, relacionamentos interpessoais tornam-se conturbados, conflitos familiares acirrados, provocando um adoecimento extendido a outros membros, entre outras devastações.

Tantos outros transtornos estão estruturados e notificados na escala do DSM-V as fobias, ansiedade, além dos transtornos depressivos. De maneira mais objetiva, neste estudo, um breve destaque para as questões da depressão e ansiedade, como adoecimento que acarreta um prejuizo significativo no processo de escolarização e aprendizagem, especialmente quando não é identificado e avaliado, em tempo habil. As informações e análises que permearam a história escolar de jovens e adolescentes mostram um retrato do desamparo que muitos deles vivenciam em seu cotidiano, em seus diversos espaços de insersão. 
O capítulo dos Transtornos Depressivos ganhou novos diagnósticos no DSM-V, levantando discussões sobre a 'patologização' de reações normais e a superestimativa do número de casos de depressão, especialmente em adolescente e jovens. $\mathrm{O}$ termo depressão tem origem no latim depressus, ato de deprimir-se. Segundo Teodoro (2010), a depressão é classificada como transtorno mental, que envolve uma complexa interação entre fatores orgânicos, psicológicos e ambientais. São comuns na depressão sintomas de angústia, rebaixamento de humor, perda de interesse, apatia, choro persistente, sentimento de impotência, perda de prazer e energia frente à vida. De acordo com Barbosa, Macedo e Silveira (20II), a ideação suicida também é um sintoma da depressão.

O psiquiatra Rafael Teixeira de Souza, em seu capitulo I página 4, do livro Depressão guia prático editora Manole,2020 teceu importantes contribuições a respeito da genética da depressão, quando descreve as interações gene-ambiente e as influências das alterações de regulação epigenética. Discorre sobre o eixo hipotálamo-pituitária (hipofise)Adrenal (eixo HPA). O eixo HPA é central no modelo neurobiológico que busca entender as consequências do trauma precoce e sua associação com a depressão, ao mesmo tempo em que explica a hiperatividade do eixo HPA e sua relação biologica entre depressão e as condições médicas como doenças cardiovasculares, hipertensão arterial sistêmica, alzheimer, obesidade, entre outros. Argumenta ainda, sobre as alterações inflamatorias e do eixo HPA, o quanto influenciam o cérebro em nivel celular, na neuroplasticidade e neurogenese (processo de formação de novos neurônios). Mesmo considerando improvavel a morte neural nos quadros depressivos, as evidências sugerem que haja perdas de sinapse ou "apoptose sinaptica".

Em relação ao transtorno de anisiedade, Graeff (2014) argumenta que os critérios e classificações das doenças mentais foram, por longo tempo, subjetivos, o que levava à discordância entre os clínicos e, sobretudo, dificultava a pesquisa científica. Por esse motivo, foram adotados critérios operacionais padronizados, que fundamentaram o atual código Internacional de doencas (CID), assim como o DSM, largamente usados em estudos clínicos. A etiologia deste transtorno aponta para a prevalência entre predisposição e ambiente. Enfatiza ainda, que é dificil traçar uma linha divisória entre a ansiedade normal, 
adaptativa e a patológica. Considera-se, portanto, ansiedade patológica o formato excessivo, persistente, desproporcional ao evento provocador, que determina sofrimento significativo prejudicando o funcionamento social e ocupacional.

Em relação ao tratamento destes transtornos, o suporte com o uso da Saúde Mental se justifica, assim, por ser uma área de conhecimento que, mais do que diagnosticar e tratar, liga-se à prevenção e promoção de saúde, preocupando-se em reabilitar e reincluir o paciente em seu contexto social. Dessa forma é pertinente descrever sobre a dolescencia e o adolescer a fim de contribuir para maiores esclarecimentos sobre o contexto da avaliação neuropsicologia e suas contribuições com o processo de aprendizagem e escolarização.

Antes de adentrar em contexto das narrativas sobre o que significa adolescência, vislumbram-se importantes contribuições para o leitor, em especial para o entendimento das discussões aqui tratadas, a respeito deste processo de escolarização afetado pelos transtornos mentais, em período de adolescência. Para tanto, ressalta-se que a adolescência é marcada por muita vulnerabilidade e busca de novas referências no mundo extra familiar. Sudbrack et.al (2003,p.5I) são muitas as adolescências, algumas intermináveis, outras muito curtas. Compreende-se, a partir desta citação, que a adolescencia é um periodo de busca de afirmação diferenciação e identidade.

A adolescência pode ser entendida como a fase de desenvolvimento que ocorre entre a infância e a vida adulta. Mudanças significativas ocorrem neste período, tanto físicas, psicológicas, cognitivas e socioculturais, sendo considerado, por alguns autores, como período esperado de crise (CARTER; MCGOLDRICK, 200I).

A Organização Mundial da Saúde (OMS, 2014), destaca que o período da adolescência está localizado dos ıo aos 19 anos de idade, sendo subdividido em fase inicial (dos io aos 14 anos) e fase final (dos 15 aos 19 anos). Entretanto, para além das idades, o conceito de adolescência se transforma com as mudanças da sociedade em um interjogo entre a evolução na estrutura do pensamento, na forma como o indivíduo compreende seu contexto social, em meio às pressões advindas deste mesmo contexto.

O processo de individuação, que ocorre desde o nascimento até o falecimento, se intensifica no período da adolescência. Com isso, são esperados o questionamento dos 
valores provenientes da família de origem e a busca por outras referências. Esse movimento se dá, normalmente, através dos pares, sendo importantíssimas nesse período as relações sociais de amizade (BOHOSLAVSKY, 2007; LEVY, 2013). É comum o adolescente não se separar dos amigos mais próximos, se afetando de forma profunda pelos valores e julgamentos dos colegas. Esse processo é chamado de uniformidade e traz segurança ao adolescente (BRASIL, 2017).

Nesta perspectiva de retratar aspectos relevantes da adolescência, o item seguinte, que aborda o processo de aprendizagem humana, de certa forma, está correlacionado com as manifestações vivenciadas no espaço escolar, familiar e demais contextos experimentados por jovens adolescentes. Como vem nos mostrando a literatura, esses adolescentes naufragam de forma assustadora, em suas interlocuções, agregando, cada vez mais comorbidades em seu quadro de transtorno de ansiedade.

Considerando, portanto, que o cérebro do adolescente ainda está em desenvolvimento, principalmente na chamada área pré-frontal, parte mais anterior do lobo frontal que é envolvida com as funções executivas, ou seja, com a elaboração das estratégias de comportamento para solução de problemas e auto-regulação do comportamento (Herculano-Houzel, 2005). Importantes considerações a respeito da memória e da regulação das emoções relacionadas ao medo, ansiedade, raiva, prazer, mantêm conexões com neurônios de áreas importantes para formação de memórias. Aprendemos aquilo que nos emociona.

\subsection{O Processo de Aprendizagem Humana}

Falar sobre a aprendizagem humana me deixa fascinada e desperta também uma vontade de expressar tudo aquilo que a imaginação pode traduzir. De que forma, esse processo, tão mágico e, ao mesmo tempo enigmático, pode ser registrado, vivenciado? A literatura costuma enfatizar que aprendizagem é um processo, troca de experiências, que necessita de criatividade, que precisa ser facilitada. Costumo imaginar aprendizagem, como algo que perpassa o tempo, espaço, lugar, cognição, as relações interpessoais e intergrupais; ultrapassa os muros da escola e suas formalidades, para atingir um lugar inimaginável, a fim de alcançar prazer,desejo, paixão, satisfação, transformação, uma mudança que nos leva a 
plenitude. Sempre fico imaginando, mesmo com todos os esclarecimentos e informações das ciências neurológicas e neurocognitivas, esse espetáculo de atos e acontecimentos que permeiam a mente humana e parecem esconder algo, que irá nos surpreender, a qualquer momento, ou seja, estejamos preparados para novas descobertas. (Lima, 2021. Grifo meu)

O homem interage, desde o nascimento, com seu ambiente, por meio dos mais variados comportamentos. Ao longo de nossas vidas, adquirimos comportamentos, que comumente são chamados de aprendizagem. Aprender é uma característica intrínseca do ser humano, essencial para sua sobrevivência (Kolb; Whishaw, 2002). O mais natural é dizerse que alguém aprende quando adquire atitudes, habilidades, conhecimentos e competências para se adaptar a novas situações, para resolver problemas, para realizar tarefas diárias importantes para a sobrevivência e para implementar estratégias em busca de saúde, de realização pessoal e em sociedade, de melhor qualidade de vida, buscando viver bem e em paz. Dessa forma, pode-se inferir que o papel da educação é proporcionar o desenvolvimento de novos comportamentos num indivíduo, oferecendo-lhe recursos que lhe permitam transformar sua prática e o mundo em que vive. Para além do espaço escolar, a aprendizagem, por sua vez, requer várias funções mentais como atenção, memória, percepção, emoção, função executiva, entre outras. Depende, portanto, do cérebro. Se a aprendizagem depente do bom funcionamento das funções cerebrais, do ambiente e também de recursos metodológicos, importantes indagações podem ser traçadas, a partir da revisão da literatura quando aponta a respeito das alterações eixo hipotalamo-pituitária (hipofise)Adrenal (eixo HPA) em portadores de trantornos mentais. Desta forma, há de se trabalhar o processo ensino aprendizagem de maneira especifica, interdisciplinar, lúdica, com recursos e protocolos que facilitem o aprendizado de forma prazerosa. Além disso, enfatiza-se a grande importância dos recursos multissensoriais, para ativação de múltiplas redes neurais que estabelecerão associação entre si.

O uso da palavra aprendizagem, ao longo do tempo parece ter se desgastado, assim também permaneceu colado ao contexto escolar e/ou pelo menos a um sentido de lugar e espaço fisico formal. É bem verdade, que o advento da revolução digital e das tecnologias on-line, provocou uma desestabilidade nos conceitos e nas novas modalidades do processo 
ensino aprendizagem. Desta forma, a neuropsicologia, como uma ciência atuante e inovadora muito contribuirá para dismistificar velhos hábitos e paradigmas, assim como crenças arraigadas, ao longo dos séculos.

O contexto do processo de aprendizagem humana, especificamente na análise da presente pesquisa, procurou traçar uma reflexão a respeito das atitudes, omissões, assim como escassos investimentos sobre os prejuizos provocados na escolarização, que em suas manifestações de ansiedade, pânico, insucessos e baixa produtividade de desempenho escolar, não conseguiu superar suas limitações. Grande parte das instituições educacionais permaneceu com o mesmo modelo tradicional e engessado, centralizando a culpa no educando. A familia, por sua vez, sente-se impotente e aprisionada na cobrança de que a responsabilidade é muito maior da escola. Diante de tal realidade necessário se faz que sejam destacados o importante papel da neurociência e da neuropsicologia..

O cérebro é considerado o órgão da aprendizagem. Para tanto, torna-se muito importante que as estratégias pedagógicas utilizadas por educadores no processo ensinoaprendizagem, possam servir de estimulos, que produzem a reorganização do SN em

desenvolvimento, resultando em mudanças comportamentais. Dioturnamente, atores sociais como pais, educadores, professores e educadores, atuam como agentes nas mudanças neurobiológicas que levam à aprendizagem, embora conheçam muito pouco sobre como o cérebro funciona (Scaldaferri; Guerra, 2002; Coch; Ansari, 2009).

Dessa forma, Lima (2017) corrobora com informações pertinentes quando aponta a complexidade do contexto das dificuldades pedagógicas e de aprendizagem, que permeiam o cenário da educação brasileira, a falta de clareza, assim como a confusão de sentido e de ideias, que tornam cada vez mais prejudicadas as ações de intervenções e as aquisições do processo ensino aprendizagem de maneira prazerosa e eficaz.

Brandão (2014), em seu livro neurobiologia dos transtornos mentais, capitulo V, aborda, com propriedade, sobre os transtornos de ansiedade e destaca as principais diferenças entre medo e ansiedade. Argumenta, ainda, a respeito das alterações hormonais, principalmente a ativação do eixo hipotálamo-pituitária-adrenal (HPA). É difícil traçar uma linha divisória entre ansiedade normal, adaptativa e a patológica, afirma Brandão. Os níveis 
de vigilância e eficiência de desempenho de tarefas intelectuais podem alterar a qualidade das relações interpessoais, prejudicando o funcionamento social e ocupacional. O estudo aprofundado a respeito dos diferentes graus de determinação genética da ansiedade, muito pode contribuir para esclarecer evidências de transmissão familiar em relação às fobias e à ansiedade.

Antes de apontar as contribuições da neuropsicologia, importante situar o conceito desta ciência que é por definição interdisciplinar e constitui-se como um campo de trabalho e investigação de várias áreas do conhecimento e de atuação profissional, que se interessam pelas relações entre funções mentais e sistema nervoso central, dentro de um universo mais amplo, denominado Neurociências, que, em sua origem, busca uma estreita relação entre os processos mentais e o funcionamento cerebral, utilizando conhecimento das neurociências, que elucidam a estrutura e o funcionamento cerebral, e da psicologia, que expõe a organização das operações mentais e do comportamento (Seron, 1982). Enquanto ciência, a neuropsicologia se ocupa das relações cérebro/funções cognitivas, ou seja, das funções cognitivas e suas bases biológicas (Rodrigues, 1993).

A literatura é bastante rica e ampla ao trazer à tona diversos contextos de definições a respeito da função e do conceito da neuropsicologia. Para tanto, define-se também como uma ciência dedicada a estudar a expressão comportamental, emocional e social das disfunções cerebrais (Lezak et al., 2004), os déficits em funções superiores produzidos por alterações cerebrais (Barbizet \& Duizabo, 1985), as inter-relações entre cérebro e comportamento, cérebro e funções cognitivas (Luria, 1966) e, de forma mais ampla, as relações entre cérebro e comportamento humano (Benton,197ı).

Pode-se evidenciar as contribuições da neuropsicologia nos seguintes pontos: estudo, observação, análise clínica, em especial, nas funções que são inseridas e estudadas de forma aprofundada, tais quais: atenção, percepção, orientação auto-psíquica, temporal e espacial, linguagem oral e escrita, memória, aprendizagem, funções motoras, praxias raciocínio, cálculos e funções executivas.

A avaliação neuropsicológica apresenta como objetivo investigar as funções cognitivas por meio de instrumentos, protocolos, testes e escalas aprovados por estudos 
científicos internacionais. Nela, o profissional é capaz de avaliar o desempenho das habilidades do paciente em diversas áreas, tais como: raciocínio, memória, atenção, percepção, abstração, aprendizagem, processamento da informação, afeto, habilidades motoras e executivas.

Seabra \& Capovilla, 2009 argumentam a referência da neuropsicologia, como uma ciência que busca relacionar a atividade do sistema nervoso o funcionamento psicológico, tanto em condições normais, quanto em condições patológicas, o que inclui o estudo do desenvolvimento e dos distúrbios cognitivos, emocionais e de personalidade. Estes mesmos autores e outros (Camarazza \&Coltheart,2006) apresentam informações a respeito da neuropsicologia cognitiva e sua importância frente aos transtornos de aprendizagem, padrões de desempenho atípico, em população afetada por lesões diversas. Estabelecem também uma distinção especifica a respeito das contribuições desta área sobre disfunções neurológicas e distúrbios do desenvolvimento, porém, não coadunam com a ideia da neuropsicologia cognitiva ser uma subárea da psicologia, uma vez que esta postura poderia limitar o avanço do conhecimento da área, promovendo seu isolamento face ao desenvolvimento da neurociência (MacGeer,2007).

A cognição humana é multidimensional, conforme citado por (Fonseca \&Prando e Cardoso 2016) formada por diversas funções cognitivas tais como atenção, memoria, linguagem, percepção, funções executivas entre outras. É por meio dessas diversas funções que as informações disponíveis no mundo são percebidas, assimiladas, processadas e, da mesma forma, são modificadas e reorganizadas. Existe um princípio da modularidade, as cognições processam informações especificas, porém existe um inter-relação entre elas. É possível identificar, portanto, que o sistema cognitivo realiza, constantemente, a síntese declarativa das experiências acessível à representação consciente.

Neste conjunto de informações é importante compreender o conceito e a importância das funções executivas, que podem ser entendidas como um conjunto de funções demandadas em situações que exigem controle de atenção, planejamento e metas e um comportamento intencional e direcionado à realização de objetivos. Esse conjunto de funções é necessário para que o indivíduo possa apresentar comportamentos complexos e 
encadeado sistematicamente, tanto em contexto de interação social, quanto em situações cognitivas complexas. As FE têm um papel importante em integrar e gerenciar as diferentes funções neuropsicológicas.

No contexto de aprendizagem humana, descreve-se a respeito da chega da escolarização, bem como seu conceito e vigência de significado até os dias atuais. A literatura aponta que a escolarização no Brasil teve seu início a partir de 1549, com a chegada dos jesuítas para a catequização dos índios à fé católica, conforme a história da educação brasileira nos apresenta. $\mathrm{O}$ objetivo de catequizar e instituir uma nova cultura aos indigenas foi conhecido como alfabetização pela fé.

Sabe-se que muitas foram as mudanças em relação a escolarização brasileira. Nesse sentido, Johann (2008) destaca a continuidade de profundas discriminações, preconceitos, desigualdades sociais, formação e reprodução de uma cultura religiosa cristã bastante rígida. Alguns dos fatos históricos que exemplificam o desenvolvimento dessa cultura de desigualdades caracterizam-se pela meritocracia e através da criação das primeiras escolas, franqueadas apenas para homens brancos que faziam parte da elite brasileira. Somente após muito tempo houve o início da educação escolar de mulheres, mestiços, negros e trabalhadores.

Ainda em relação ao processo de escolarização, Bossa (2002) refere que:

a escola, que deveria formar jovens capazes de analisar criticamente a realidade, a fim de perceber como agir no sentido de transformá-la e, ao mesmo tempo, preservar as conquistas sociais, contribui para perpetuar injustiças sociais que sempre fizeram parte da história do povo brasileiro. É curioso observar o modo como os educadores, sentindo-se oprimidos pelo sistema, acabam por reproduzir essa opressão na relação com os aluno Bossa (2002, p. 190).

Neste sentido, sobre o processo de escolarização, Arrayo (1992) argumenta que:

\footnotetext{
a escola enquanto instituição - não enquanto boas vontades de seus mestres - mantém a mesma ossatura rígida e excludente já faz um século. Continua aquela estrutura piramidal, preocupada apenas com o domínio seriado e disciplinar de um conjunto de habilidades e saberes. A ultrapassagem de domínios preestabelecidos em cada disciplina e em cada série é precondição para a manutenção ou a perda irrecuperável do direito a uma experiência sociocultural formadora. (ARROYO, 1992, p. 47).
} 
Depreende-se a importância da compreensão sobre o sentido da aprendizagem humana, em especial no espaço escolar, assim como a necessidade fundamental da avaliação psicologia e neuropsicologica para a condução do processo de intervenção e reabilitação. Neste sentido, o item a seguir indaga a construção e o desenvolvimento dos transtornos mentais na convivência do ambiente familiar.

\section{2 Ambiente Familiar e o Contexo das Aprendizagens}

A família é uma instituição social que sofre modificações ao longo do tempo, sendo que, historicamente, se observam várias formas de relações familiares (Prado, I98ı; Narvaz \& Koller, 2006). Podemos afirmar ainda, baseando-nos em Prado (198I), Narvaz e Koller (2006) que uma família se constitui por relações expressas diferentemente de acordo com o tempo, o lugar e os papéis que cada um desempenha.

A convivência familiar, em ambiente marcado por adoecimento mental de um dos genitores requer atenção especial e uma condução sobre os aspectos de saúde mental, no que tange à prevenção, ao cuidado e autocuidado de cada membro nas fases do biociclo familiar, que pode se caracterizar pela "passagem" e o "cumprimento" de tarefas específicas ao longo do desenvolvimento humano e das vivências relacionais familiares. Os critérios que as definem compreendem alguns marcos nodais, como: idade do filho mais velho, idade dos pais, tempo de união de um casal, entre outros. Ao mesmo tempo em que a passagem destes estágios, se constitui num desafio vital, no sentido de ameaçar a dinâmica da família, por outro lado, permite o desenvolvimento e a autonomia de seus membros (Cerveny, 1997).

Importante observar a citação da OMS - Organização mundial de saúde no Brasil, estimativas (OMS, 2000) apontam que haverá cerca de 34 milhões de idosos em 2025, com predominância para a faixa etária acima de 80 anos. Além disso, em 2050, estima-se que o percentual de pessoas acima de 60 anos corresponderá a cerca de 30\% da população do país (IBGE, 2008), de modo que o número de idosos no Brasil já é um dos maiores do mundo. Compreendendo a velhice como uma condição subjetiva, multidimensional, heterogênea, e que varia de indivíduo para indivíduo, uma vez que tais variações são dependentes de vários fatores como estilo de vida, condições socioeconômicas, doenças crônicas entre outras. 
Notadamente, no que diz respeito aos transtornos especificos de aprendizagem, os mesmos deixaram de ser subdivididos em transtornos de leitura, cálculo, escrita e outros, especialmente pelo fato de que indivíduos com esses transtornos, frequentemente, apresentam déficits em mais de uma esfera de aprendizagem. Dessa forma, uma indagação provocada no contexto deste estudo. Transtornos mentais, provocam dificuldades de aprendizagem? Acredita-se, de acordo com a literatura já descrita neste artigo, que dificuldades de aprendizagem compõem-se de diversos fatores: orgânicos, ambientais, fisicos e neurobiologicos; portanto, não existe um único fator que seja determinante. A ausência de avaliação psicológica interfere no processo ensino aprendizagem? Percebe-se como é de fundamental importancia a investigação apurada de diagnóstico clínico para nortear o processo de intervenção, assim como ações psicoeducacionais, que servirão para orientar a rotina, tanto familiar quanto instrucional do sujeito na clínica. A avaliação psicológica é um procedimento rico, dinâmico que traduz elementos inconscientes, que muito contribuirão para a superação das dificuldades e do adoecimento psíquico. $O$ procedimento técnico da avaliação psicológica refere-se aos instrumentos, bem como as consequências éticas de suas aplicações. Implica elaboração e escolha de instrumentos, aplicação e resultados. É um equivoco visualizá-la somente como geradora de um produto (PELLINI;LEME.20II). Portanto, a avaliação psicológica é recorrente em vários contextos desde a academia, se estendendo para a prática profissional.

Para tanto, o psicólogo deve se utilizar de estratégias de avaliação psicológica com objetivos bem definidos para encontrar respostas às questões propostas, com vistas à soluções de problemas, (CUNHA, 2002). Cabe salientar que a ausência da avaliação psicologica, enquanto constructo de excelência para a apuração dos fenomenos psíquicos, neste processo do "conhecer-se" e "perceber-se", irá impactar diretamente no retardo das ações de intervenção, assim como no resultado do processo ensino aprendizagem provocando instabilidade, insegurança e incerteza, quanto a aplicação de práticas educativas e terapeuticas, pelos profissionais, ressoando logicamente nos sujeitos envolvidos.

Outros fatores também influenciam a aprendizagem (Rotta; Ohlweiler; Riesgo, 2006). Estes autores destacam importantes informações que permeiam o ambiente escolar e 
as intervenções e que, quase sempre, são desprezadas. Pode-se citar: a) Aprendizes privados de material escolar adequado; b) de ambiente para estudo em casa; c) de acesso a livros e jornais, de incentivo ou estímulo dos pais e/ou dos professores; d) pouco expostos a experiências sensoriais, perceptuais, motoras, motivacionais e emocionais, essenciais ao funcionamento e reorganização do $\mathrm{SN}$, podem ter dificuldades para a aprendizagem, embora não sejam portadores de alterações cerebrais. Transtornos psiquiátricos, como o transtorno do déficit de atenção e hiperatividade (TDAH) e depressão, que demandam orientação médica e tratamento, podem dificultar a aprendizagem.

Neste contexto da clinica com pacientes com demanda de transtornos mentais e prejuizos escolares, marcados por reprovações e problemas adaptativos, afetivo-relacionais, agressividade, medo, pânico, entre outros comportamentos, constituem verdadeiros desafios, tanto para o contexto escolar, que precisa apresentar o conhecimento em um formato que o cérebro aprenda melhor, promovendo possibilidade de discussão, sem ameaça, assim como o espaço de escuta terapeutica que precisa abrir-se em possibilidades de resignificação, realizando uma interseção entre as ciências acerca das patologias e das angústias do não-aprender.

\section{CONSIDERAÇÕES FINAIS}

O presente estudo buscou discutir, à luz dos pressupostos da neuropsicologia e da neurociência, os transtornos mentais e sua correlação com a escolarização e as dificuldades de aprendizagem em jovens adolescentes. Após exaustivas leituras de livros, artigos, revistas, ensaios, e-books e plataformas virtuais, entre outros, o resultado da pesquisa constatou a complexidade de informações, sintomas e características que envolvem os transtornos mentais, assim como as principais dificuldades de engajamento científico e estrutural, para o planejamento das intervenções educacionais, terapêuticas, familiares, sociais e emocionais, diante do processo de escolarização e das dificuldades de aprendizagem. As narrações e interlocuções formaram um recorte interdisciplinar nos diversos contextos de inserção de jovens adolescentes procurando abarcar as necessidades mais urgentes dos prejuízos emocionais e de aprendizagem. A pesquisa sobre esta temática precisa ser 
aprofundada, a fim de que a complexidade e o "pavor" que permeia o referencial desta abordagem sobre os transtornos mentais, possam ser superadas em benefício do sucesso escolar e do bem-estar dos jovens adolescentes.

O conhecimento neurobiológico e da neurociência, cada vez mais abrangente e dinâmico, tem se tornado imprescindivel ao contexto de vivência do cotidiano humano. As contribuições da neurociência, para fundamentar a prática educacional, passou a ser uma exigência da contemporaneidade, em especial para compreender o processo das dificuldades de aprendizagem, além de inovar as práticas educativas no que diz respeito a aplicação dos recursos multisensoriais e metodológicos, assim como as intervenções terapeuticas. Dessa forma, imagina-se a necessidade de uma reflexão sobre as possibilidades e desafios do diálogo entre a neurociência e a educação. Tais interlocuções podem trazer avanços significativos para ambas as áreas, uma vez que conhecer como o cérebro funciona pode ajudar a facilitar a via de acesso ao entendimento pedagógico das relações de aprendizagem.

A evolução da Neuropsicologia tem como base a rota histórica dos estudos do comportamento e do cérebro. Nesta perspectiva pode-se indagar, quando ocorre a não aprendizagem, o problema está no cérebro? Claro que não. Múltiplas variáveis concorrem para a formação das dificuldades, entre elas fatores metodológicos, sociais, econômicos, familiares, entre outros.

O trabalho realizado trouxe à tona a necessidade de abertura de diálogo entre escola, profissionais da educação e psicologia, tendo como objetivo maior, o atendimento o mais precoce possível, visando o bem-estar e a fluência do aprendizado do indivíduo que apresenta algum transtorno mental que implique em sofrimento no ambiente escolar.

\section{REFERÊNCIAS BIBIOGRÁFICAS}

AMARAL, Osvaldo Lopes . Transtornos mentais. Instituto de Estudos e Orientação da Família. Água Branca SP.e-mail: mailto:inef@osite.com.br, 2orr.

AMARAL, Osvaldo Lopes. Instituto de estudos e orientação da família do portador de transtorno mental. Revista Nacional de Reabilitação, n. 40, mar.2003. 
American Psychiatry Association. Diagnostic and Statistical, 2013

ANSARI, D. Paving the way towards meaningful interactions between neuroscience and education. Developmental Science, v. 8, n. 6, p. 467-467, 2005.

ARROYO, Miguel G. Fracasso-sucesso: o peso da cultura escolar e do ordenamento da educação básica. Em aberto, Brasília, ano II, n.53, p. 46-53, jan/mar. 1992.

BARBIZET, J., \& DUIZABO, P. (1985). Manual de Neuropsicologia. Porto Alegre: Artmed.

BARBOSA, Fabiana de Oliveira; MACEDO, Paula Costa Mosca and SILVEIRA., Rosa Maria Carvalho da. Depressão e o suícido. Rev. SBPH, Jun 20II, vol.ı4, no.I, p.233-243. ISSN $1516-0858$

BENTON, A. L. Introducción a la neuropsicología. Barcelona: Fontanella, I97ı.

BLAKE, P.R.; GARDNER, H. A first course in mind, brain, and education: Mind, Brain, and Education, v.I, p. 032007.

BLAKEMORE, S.J; FRITH, U. The learning brain: lessons for education. Oxford: Blackwell Publishing, 2005.

BOHOSLAVSKY, R. Orientação Vocacional a estratégia clínica. São Paulo: Martins Fontes, 2007. 218

BOSSA, Nádia A. Fracasso Escolar: Um olhar psicopedagógico. São Paulo: Artmed, 2002. BRANDÃO, L. M; GRAEFF, Frederico Guilherme. Neurobiologia dos Transtornos Mentais. São Paulo: Ateneu, 20I4. 
CARAMAZA, A., \& COLTHEART, M. (2006). Cognitive neuropsychology twenty years on. In M. Coltheart \& A. Caramazza (Eds.), (pp. 3-12). New York: Psychology Press.

CAPOVIlla, F. C. (2010). (Org.). Transtornos de aprendizagem: Progressos em avaliação e intervenção preventiva e remediativa. São Paulo, SP: Memnon. (ISBN: 978-857954-012-7).

CARTER, B.; MCGOLDRICK, M. As Mudanças no Ciclo de Vida Familiar: uma estrutura para a terapia familiar. Porto Alegre: Artmed, 200 .

CERVENY, C. M. O., BERTHOLD, C. M. E. \& col. (1997). Família e ciclo vital: nossa realidade em pesquisa. São Paulo: Casa do Psicólogo.

$\mathrm{COCH}$, D.; ANSARI, D. Thinking about mechanisms is crucial to connecting neuroscience and education. Cortex, v. 45, n. 4, p. 546-547, 2009.

CONSELHO NACIONAL DE PESQUISA DOS ESTADOS UNIDOS. Como as Pessoas Aprendem: Cérebro, Mente, Experiência e Escola. São Paulo: Editora Senac, 2007.

COSENZA, R. M.; GUERRA, L. B. Neurociência e educação: como o cérebro aprende. Porto Alegre: Artmed, 20II. p. I4I-I48.

CUNHA, J.A. Psicodiagnóstico - V. Porto Alegre: Artmed, 2002.+

DALGALARRONDO, Paulo. Psicopatologia e semiologia dos transtornos mentais. 2. ed. Porto Alegre: Artmed, 2008.

DSM-V-TRTM - Manual diagnóstico e estatístico de transtornos mentais. trad. Cláudia Dornelles; - 5.ed. rev. - Porto Alegre: Artmed, 2013. 
FONSECA , PRANDO \& CARDOSO, Avaliação de linguagem e Funções Executivas em Crianças. Mennon São Paulo. 2016 -P.ıI

GIL, R. Neuropsicologia. 4. ed. São Paulo: Santos, 2014· p. I-19.

GRAEFF, Frederico Guilherme; BRANDÃO, M. L, Neurobiologia dos transtornos mentais , cap. 5, p I32-16ı, Transtorno de Ansiedade, Atheneu São Paulo, 2014

GUERRA, Leonor Bezerra. O Diálogo entre a Neurociência e a Educação: da Euforia aos Desafios e Possibilidades. Revista Interlocução, v.4, n.4, p.3-I2, publicação semestral, junho 2011.

GUERRA, L. B. Neurociência e educação: como o cérebro aprende, $201 I$.

HELLER, Agnes. O cotidiano e a história. São Paulo: Paz e Terra, 2014.

HERCULANO-HOUZEL, S. O cérebro em transformação. Rio de Janeiro: Objetiva, 2005.

JOHANN, Jorge Renato. Educação e a Utopia da Esperança: um novo homem e uma nova sociedade. Canoas: Ed. Ulbra, 2008.

KANDEL, E. R. et al. Princípios de neurociências. 5. ed. Porto Alegre: Artmed, 2014.

KOIZUMI, H. The concept of "developing the brain": a new natural science for learning and education. Brain \& Development, v. 26, n. 7, p. 434-44I, 2004.

KOLB, B; WHISHAW, I.Q. Neurociência do Comportamento. São Paulo: Manole, 2002.

LEVY, R. O adolescente. In: EIZIRIK, C. L.; BASSOLS, A. M. S. (Ed.). O Ciclo da Vida Humana: uma perspectiva psicodinâmica. 2 ed. Porto Alegre: Artmed, 2013. p.167-179. 
LEZAK, M. D., HOWIESON, D. B. \& LORING, D. W. Neuropsychological assessment. (4th ed.). New York: Oxford University Press, 2004.

LIMA, Clinaura Maria de. Psicopedagogia: prática, vivências e experiências no espaço escola e clinica. Curitiba: Jurua, 2017.

LURIA, A. R. Higher Cortical Functions in Man. New York:Basic Books, 1966.

MACGEER, V. Why neuroscience matters to cognitive neuropsychology. Synthese, 159,347-371, 2007

MACHADO, A. B. M.; HAERTEL, L. M. Neuroanatomia funcional. 3. ed. São Paulo: Atheneu, 2014.

MANUAL DE DIAGNÓSTICO E ESTATÍSTICA DE TRANSTORNOS MENTAIS - $5^{\text {a }}$ EDIÇAO OU DSM- 5 - ASSOCIAÇÃO AMERICANA P.5

Manual of Mental disorders - DSM-5. 5th.ed. Washington:

MUNIZ, I. A Neurociência e as emoções: quem não sabe sorrir, dançar e brincar não deve ensinar do ato de aprender. Bahia: Via Litterarum, 2012. p. 17-40.

NARVAZ, M., KOlleR, S. H. A invenção da família. Revista Pensando Famílias, 7 (9), I2I134, 2006

OLIVEIRA, L.; PEREIRA, M. G.; VOLCHAN, E. Processamento emocional no cérebro humano. In: LENT, T. (coord.). Neurociência da mente e do comportamento. Rio de Janeiro: Guanabara Koogan, 2016.

ORGANIZAÇÃO MUNDIAL DE SAÚDE. Saúde para os adolescentes do mundo: uma segunda chance na segunda década. Genebra: Organização Mundial da Saúde; 2014. 
ORGANIZAÇÃO MUNDIAL DE SAÚDE. Health Systems: Improving Performance (Relatório Mundial de Saúde). Genebra (Suiça), 2000.

PELLINI, M. C. B. M., \& LEME, I. F. A. S. (20II). A ética no uso de testes no processo de avaliação psicológica. In R. A. M. Ambiel, I. S. Rabelo, S. V. Pacanaro, G. A. S. Alves, \& I. F. A. S. Leme (Orgs). Avaliação psicológica: Guia de consulta para estudantes e profissionais de psicologia (pp. 163-180). São Paulo, SP: Caso do Psicólogo.

PRADO, D. O que é família? São Paulo: Brasiliense, I98I.

SOUZA, Rafael Teixeira. Alterações fisiopatologicas da depressão, capitulo I in livro Depressão: Depressão guia prático, editora Manole, Barueri São Paulo. 2020 .

REY, L. Dicionário de termos técnicos em Medicina e Saúde. Rio de Janeiro: Guanabara Koogan, 1999.

RODRIGUES, N. Neuropsicologia: uma disciplina científica. Em: Rodrigues, N. \& Mansur, L. L. (Eds.). Temas em neuropsicologia, I, I-I8. São Paulo: Tec Art, 1993.

ROTTA, N.T., OHLWEILER, L., RIESGO, R.S. Transtornos da aprendizagem: abordagem neurobiológica e multidisciplinar. Porto Alegre: Artmed, 2006.

ROUCO, Maria. Beatriz. Simões. Neuropsicanálise: articulação necessária e fértil. In. NAZARETH, Eliana Riberti; BÉJAR, Victoria. Regina (Org.). Imunidade, memória, trauma: contribuições da neuropsicanálise, aportes da psicossomática psicanalítica.r ed. São Paulo: Blucher, 2020. 
SCALDAFERRI, P. M.; GUERRA, L. B. A inserção da neurobiologia na educação. In: X SEMANA DE INICIAÇÃO CIENTÍFICA E II SEMANA DO CONHECIMENTO DA UFMG, Belo Horizonte: Anais, 2002. p. 6I

SEABRA, A. G., \& COPOVILLA, F.C. Problemas de leitura e escrita: como identificar, prevenir e remediar numa abodardagem fônica, 6 ed. São Paulo: Memnon, 2011.

SEABRA, A. G, Dias nm. Avaliação neuropsicológica cognitiva: atenção e funções executivas. Vol. I. São paulo: Memnon; 2012. SEABRA, A. G, Dias nm. Avaliação neuropsicológica cognitiva: linguagem oral. Vol. 2. São paulo: memnon; 2012.

SEABRA, A. G. Avaliação psicoeducacional infantil. In J. M. Montiel \& F.Capovilla (org) Atualização em transtorno de aprendizagem (caps) São Paulo SP: Artes médicas, 2009

SERON, X. Toward a cognitive neuropsychology. International Journal of Psychology, i7, 149-156. 1982

SOUSSUMI, Yusaku .O corpo sensível e a lógica da vida: neuropsicanálise. In. NAZARETH, Eliana Riberti; BÉJAR, Victoria. Regina (Org.) Imunidade, memória, trauma: contribuições da neuropsicanálise, aportes da psicossomática psicanalítica.r ed. São Paulo: Blucher, 2020.

SUDBRACK, Maria Fátima O. Da obrigação à demanda, do risco à proteção e da dependência à liberdade: abordagem da drogadição de adolescentes em conflito com a lei. Em SUBBRACK, Maria Fátima O; CONCEIÇÃO, Maria Inês G; SEIDL, Eliane M. F \& SILVA, Maria Terezinha, (Org), Adolescentes e drogas no contexto da Justiça (pp. 47-8o), Brasília: Plano, 2003

TEODORO, W. L. G. Depressão: corpo, mente e alma. Uberlândia -MG, 2010. (p. 20-4647) ISBN: 978-85-61353-or-8. 3 Edição. 
TERUEL, F. M. Neuroeducación: solo se puede aprender aquello que se ama. Madrid: Alianza Editorial S. A. 2013.

VIVAN, D. Aplicação de diretrizes da ciência da mente, cérebro e educação á produção de vídeos educacionais. Dissertação (Mestrado em Design) -Faculdade de Arquitetura, Universidade Federal do Rio Grande do Sul, Porto Alegre, 2012. 